\title{
Consultation and Surgical Wait Times in Cervical Spondylotic Myelopathy
}

\author{
Babak Sharifi, Greg McIntosh, Charles Fisher, W. Bradley Jacobs, \\ Michael Johnson, Christopher S. Bailey, Sean Christie, Raphaële Charest-Morin, \\ Jérome Paquet, Andrew Nataraj, David Cadotte, Neil Manson, Hamilton Hall, \\ Kenneth C. Thomas, Y. Raja Rampersaud, Nicolas Dea
}

ABSTRACT: Background: Cervical spondylotic myelopathy (CSM) is the leading cause of spinal cord impairment. In a public healthcare system, wait times to see spine specialists and eventually access surgical treatment for CSM can be substantial. The goals of this study were to determine consultation wait times (CWT) and surgical wait times (SWT), and identify predictors of wait time length. Methods: Consecutive patients enrolled in the Canadian Spine Outcomes and Research Network (CSORN) prospective and observational CSM study from March 2015 to July 2017 were included. A data-splitting technique was used to develop and internally validate multivariable models of potential predictors. Results: A CSORN query returned 264 CSM patients for CWT. The median was 46 days. There were $31 \%$ mild, 35\% moderate, and 33\% severe CSM. There was a statistically significant difference in median CWT between moderate and severe groups; 207 patients underwent surgical treatment. Median SWT was 42 days. There was a statistically significant difference in SWT between mild/moderate and severe groups. Short symptom duration, less pain, lower BMI, and lower physical component score of SF-12 were predictive of shorter CWT. Only baseline pain and medication duration were predictive of SWT. Both CWT and SWT were shorter compared to a concurrent cohort of lumbar stenosis patients $(p<0.001)$. Conclusions: Patients with shorter duration (either symptoms or medication) and less neck pain waited less to see a spine specialist in Canada and to undergo surgical treatment. This study highlights some of the obstacles to overcome in expedited care for this patient population.

RÉSUMÉ : Temps d'attente pour obtenir une consultation et une intervention chirurgicale dans le cas de la myélopathie spondylotique cervicale. Contexte : La myélopathie spondylotique cervicale (MSC) est la principale cause des troubles de la moelle épinière. Dans un régime public de santé, les temps d'attente pour voir des spécialistes et, le cas échéant, pour avoir accès à un traitement chirurgical dans le cas de la MSC peuvent être considérables. Cette étude comporte deux objectifs : d'une part, déterminer les temps d'attente pour une consultation (TAC) et pour une intervention chirurgicale (TAIC); d'autre part, identifier les variables prédictives des temps d'attente. Méthodes : C'est dans le cadre du Canadian Spine Outcomes and Research Network (CSORN) que cette étude observationnelle prospective a été effectuée. Y ont participé des patients vus un à la suite de l'autre entre mars 2015 et juillet 2017. À cet égard, nous avons utilisé la méthode de fractionnement des données (data-splitting technique) pour développer et valider à l'interne des modèles concernant nos variables prédictives. Résultats : Les données du CSORN montrent que 264 patients atteints de MSC sont parvenus à obtenir une consultation. Leur TAC médian a été de 46 jours. Sur ces 264 patients, $31 \%$ étaient atteints d'une forme légère de MSC ; $35 \%$, d'une forme modérée ; et $33 \%$, d'une forme grave. Une différence statistique notable est apparue en ce qui regarde le TAC médian du groupe de patients atteints de la forme modérée de la maladie et celui du groupe de patients atteints de la forme grave. Notons par ailleurs que 207 patients ont pu subir une intervention chirurgicale. Leur TAIC médian a été de 42 jours. Une différence statistique notable est apparue entre les groupes de patients atteints des formes légère/ modérée et celui incluant des patients atteints de la forme grave. Des symptômes de courte durée, moins de douleurs ressenties, de bas IMC et des scores plus bas au SF-12 en matière de santé physique ont constitué des variables prédictives d'un TAC plus court. Les seules variables ayant pu prédire les TAIC ont été le niveau de douleur avant traitement et la durée d'un traitement médical. Enfin, tant les TAC que les TAIC des patients atteints de MSC se sont révélés plus courts que ceux d'une cohorte de patients atteints de sténose du canal lombaire $(\mathrm{p}<0,001)$ étudiée simultanément. Conclusions : En somme, les patients dont la durée des symptômes ou du traitement médical était plus courte, de même que ceux ayant moins souffert de cervicalgie, ont moins

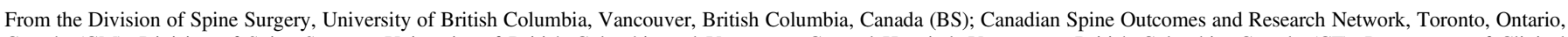

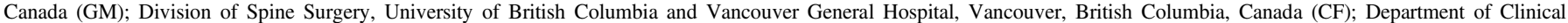

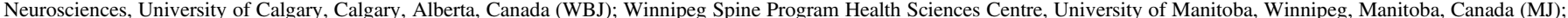

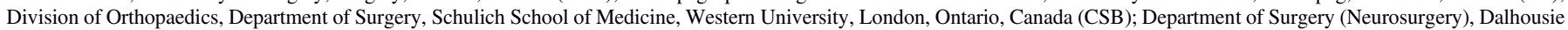

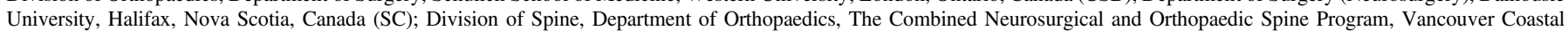

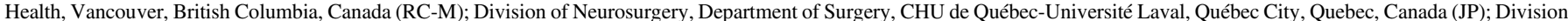

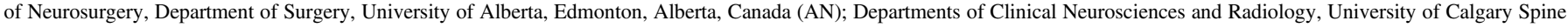

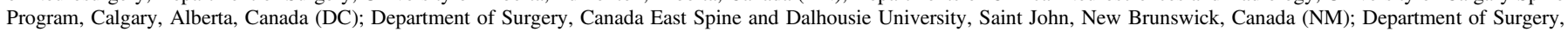

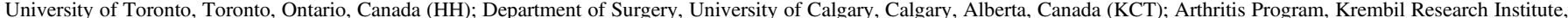

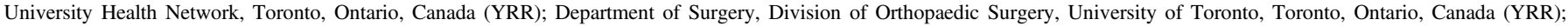
Combined Neurosurgery and Orthopaedic Spine Program, University of British Columbia, Vancouver, British Columbia, Canada (ND).

Received August 31, 2018. Final Revisions Submitted March 6, 2019. Date of Acceptance March 12, 2019.

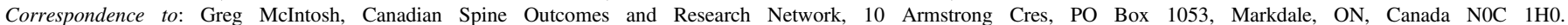
Email: gmcintosh@spinecanada.ca 
attendu au Canada pour voir un spécialiste de la moelle épinière et subir une intervention chirurgicale. Cette étude met donc en relief certains obstacles à une offre de services rapides pour cette catégorie de patients.

Keywords: Wait times, Cervical, Myelopathy, Prediction

doi:10.1017/cjn.2019.34

Can J Neurol Sci. 2019; 46: 430-435

\section{BACKGROUND}

Cervical spondylotic myelopathy (CSM) is a progressive degenerative disease and the most common cause of spinal cord dysfunction worldwide. ${ }^{1}$ Its etiology is multifactorial and includes disc protrusion, ossification of the posterior longitudinal ligament, thickening of the ligamentum flavum and osteophyte formation, which result in narrowing of the spinal canal and ultimately lead to compression of the spinal cord.

Depending on the severity of the disease, symptoms can include neck pain, loss of hand dexterity, gait difficulties, and sphincter disturbance. ${ }^{2-4}$ There are multiple scoring systems used to assess the severity of cervical myelopathy. The modified Japanese Orthopedic Association (mJOA) score is among the most commonly utilized and is a recommended outcome assessment tool for these patients. ${ }^{5}$ According to this scoring system, mild myelopathy is defined as a score from 15 to 17, moderate from 12 to 14 , and severe from 0 to $11 .^{6}$

Surgery is usually indicated to halt or reverse the myelopathic symptoms. ${ }^{7,8}$ The natural history of cervical myelopathy can be a progressive decline in neurological function in a significant proportion of patients. ${ }^{9}$ Moreover, the severity of symptoms has been correlated to the likelihood of achieving a good clinical outcome with surgical decompression; patients with severe CSM are less likely to achieve a mJOA $\geq 16$ with surgery. ${ }^{10}$ Longer duration of symptoms has been correlated with poor surgical outcomes; ${ }^{11}$ therefore, prompt assessment and management are warranted to achieve better results for this patient population. In a public healthcare system, wait times to see a specialist from the time of referral (consultation wait time (CWT)) and wait times to receive surgical treatment from the time of surgical booking (surgical wait time (SWT)) can be substantial. With the increasing prevalence of CSM and the significant disease burden associated with spinal cord dysfunction for both the patients and society, it is essential to recognize factors that could be obstacles to timely management.

The primary objective of this study was to examine CWT and SWT in patients surgically assessed for CSM in the Canadian public healthcare system. Secondary objectives were to identify demographic, clinical, and radiographic factors that predict CWT and SWT in this same patient population and to compare wait times between CSM and other degenerative conditions of the spine.

\section{Methods}

\section{Study Design}

We conducted a multicentre, prospective observational study of consecutive patients with CSM enrolled in the CSORN between March 2015 and July 2017. CSORN is a group of over 50 neurosurgical and orthopedic spine surgeons from 18 tertiary care academic and non-academic hospitals across Canada that prospectively collect data on patients with spinal conditions. This database serves as a national registry created to answer research questions and to facilitate the implementation of best practices. Thirty-five surgeons from seven Canadian centers participated in this prospective CSM study.

A national database research coordinator audits data quality and performance and sends reports to each contributing hospital site coordinator on a quarterly basis. Reports track data completion and follow-up rates to facilitate internal data validation at each site. A national privacy and security framework was created for CSORN that includes a governance structure, standard operating procedures, training processes, physical and technical security, and privacy impact assessments. This model ensures privacy and security of personal health information. Written informed consent is obtained from all participating patients. Patient identification is anonymized to ensure that patients in the Network cannot be individually identified. All participating sites obtained Research Ethics Board (REB) approval prior to any data collection. Decisions regarding data collection, storage, and analysis are independent of any particular company or commercial interest.

\section{Patient Sample}

Local research coordinators enrolled patients at each site. All patients presenting to the participating surgeons with clinical signs and symptoms of CSM and MRI evidence of cord compression and/or myelopathy secondary to spondylosis were invited to participate in this study. To be included, patients also had to have referral and consultation dates available for CWT and surgical booking date and operative date for SWT. Further exclusion criteria included: previous cervical spine surgery, fracture, tumor or intradural pathology, anterior horn disease, or multiple sclerosis

\section{Patient Variables}

Baseline pre-operative patient characteristics included sociodemographic factors (age, sex, body mass index (BMI), nicotine use, education level, work status, and marital status), symptom duration, and the physical component score (PCS) of SF-12. All patients were treated in a single payer, publically administered healthcare system. These patients were stratified by CWT, SWT, as well as by the severity of the symptoms based on mJOA score. CWT was defined from the referral date to the first surgical consultation date and SWT was defined from surgical booking to the actual surgical date. Categorical data were compared using the Chi-square two-tailed tests. For demographic comparisons between wait time groups, statistical significance was achieved with a $p$-value of less than 0.05 . Survival analysis was used for identification of independent predictors of CWT and SWT within the nationwide registry. 


\section{Table 1: Demographic data for patients with CSM from the CSORN registry as stratified by CWT and SWT}

\begin{tabular}{l|c|c}
\hline Demographics & CWT & SWT \\
\hline Age (mean) & 59.4 & 60.1 \\
\hline Female & $33 \%$ & $34.8 \%$ \\
\hline Working & $27.3 \%$ & $26.1 \%$ \\
\hline Symptom < 1 year & $40.9 \%$ & $39.7 \%$ \\
\hline BMI (mean) & 28.63 & 28.79 \\
\hline
\end{tabular}

Using the CSORN database, a comparison cohort of lumbar stenosis patients enrolled during the same study period (March 2015 and July 2017) was used to contrast CSM and stenosis wait times.

\section{Statistical Analysis}

Outcomes were assessed using survival analysis. As a preliminary analysis to compare differences in survival across groups, the Kaplan-Meier (KM) method was used to estimate the survivor function of cumulative time waiting for consultation/surgery. Since not every referred patient was treated surgically, separate analyses were conducted for CWT and SWT.

Cox regression procedures were employed to find the best multivariable models predicting CWT and SWT outcomes. A data-splitting technique was used to develop and test the multivariable models. Data splitting is a method of obtaining a nearly unbiased internal assessment of accuracy. With this technique, an $80 \%$ random sample of the full data set was used for model development (BUILD sample) and the entire data set for validation (TEST sample).

Multivariable analyses were performed on the BUILD sample to identify the statistically significant variables, using a backward stepwise selection procedure. Collett ${ }^{12}$ suggests avoiding rigid application of a particular significance level with this selection procedure. To guide decisions on entering and omitting terms, the significance level should not be too small; the significance level was set at the recommended level of $10 \%$.

There were 22 potential predictors entered into regression models in clusters. The first cluster was primarily demographictype variables: age, gender, BMI, marital status, living arrangement, education level, smoking status, exercise, and comorbidity. The second cluster was clinical variables: symptom duration, numeric pain rating, medication use, medication duration, intensity, and alignment. The third cluster was patient reported questionnaires: Neck Disability Index, SF-12 (Mental Component Score (MCS) and PCS, PHQ-9, EQ-5D, and mJOA.

All significant variables from the cluster modeling procedures were then entered into a multivariable model to determine the best models predicting outcome using the same selection procedure and significance levels. This combined analysis of multiple clusters/ predictors has been previously shown to enhance the prediction of persistent pain. ${ }^{13,14}$ The outcome variables were cumulative number of calendar days waiting for consultation (CWT) and waiting for surgery (SWT). Adjusted R-squared values were computed for each final regression model. $R$-squared in survival analysis does not describe how appropriately a model fits the data because
$R$-squared can be increased just increasing the number of variables. As a result, $R$-squared in this context examines the percentage of explained variation in the regression models.

Kaplan-Meier log rank tests were conducted to compare CWT and SWT in patients with CSM to lumbar stenosis patients entered into the CSORN database.

\section{Results}

Since not every referred patient was treated surgically, descriptive results are reported separately for CWT and SWT. Table 1 displays demographic data for both CWT and SWT. No statistical difference between provinces was found for either CWT or SWT. A total of 80 (CWT) and 124 (SWT) patients were excluded from analysis because the primary outcome was not obtained.

\section{Consultation Wait Time}

Data from 264 patients were available for analysis. The median CWT was 46 days. There were $31 \%$ mild (median CWT $=40$ ), $35 \%$ moderate (median CWT $=60$ ), and $33 \%$ severe CSM (median CWT $=32$ ) based on mJOA scores. Kaplan-Meier $\log$ rank tests revealed no statistically significant difference in median CWT between mild and moderate group or mild and severe group. There was, however, a statistically significant difference $(p<0.011)$ in CWT between the moderate and severe groups (Figure 1).

\section{Multivariable Modeling}

Using the build sample, multivariable regression analysis revealed five significant predictors of shorter CWT: short symptom duration $(p<0.0001)$, less baseline neck pain $(\mathrm{p}<0.011)$, radiologic cord compression $(p<0.059)$, lower BMI $(p<0.023)$, and lower PCS scores $(p<0.106)$ (Table 2). A separate regression analysis using the test sample confirmed the same five predictors. Overall, the model explained 18\% of the variance (adjusted $R$-squared $=0.18$ ).

\section{Surgical Wait Time}

Two hundred and seven patients underwent surgery and were included in the SWT analyses. The median SWT was 42 days. There were $25 \%$ mild (median SWT $=54$ ), $40 \%$ moderate $($ median SWT $=43$ ), and $35 \%$ severe CSM (median SWT $=24)$ based on mJOA scores. Kaplan-Meier log rank tests revealed a statistically significant difference in median SWT between mild and severe groups $(p<0.005)$ and between moderate and severe groups $(p<0.017)$. There was no statistically significant difference between mild and moderate groups (Figure 2).

\section{Multivariable Modeling}

Using the build sample, multivariable regression analysis revealed only two significant predictors of shorter SWT: medication duration of less than 1 year $(p<0.002)$ and less baseline neck pain rating $(p<0.083)$ (Table 3$)$. A separate regression analysis using the test sample confirmed the same two predictors. Overall, the model explained $11 \%$ of the variance $(R$-squared $=0.11)$. 
Table 2: Regression analysis of predictors of CWT

\begin{tabular}{l|c|c|c|c}
\hline Predictor & HRR & 95\% CI (lower) & 95\% CI (upper) & $\boldsymbol{p}$-value \\
\hline Symptom duration < 1 year & 2.127 & 1.450 & 3.120 & $<0001$ \\
\hline Baseline neck pain rating & .919 & .862 & .981 & .011 \\
\hline Radiologic cord compression & 2.684 & .962 & 7.490 & .059 \\
\hline BMI & .971 & .946 & .996 & .023 \\
\hline PCS-12 & .984 & .965 & 1.003 & .106 \\
\hline
\end{tabular}

$\mathrm{HRR}=$ hazard rate ratio, $\mathrm{CI}=$ confidence interval, and PCS = Physical Component Score of the SF-12.

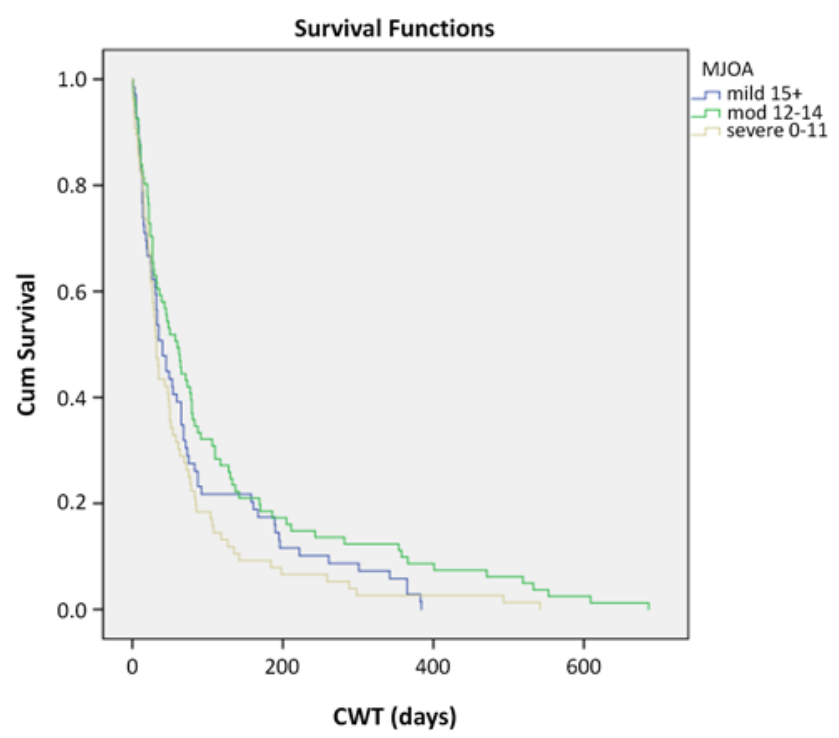

Figure 1: CWT Kaplan-Meier survival curves stratified by disease severity.

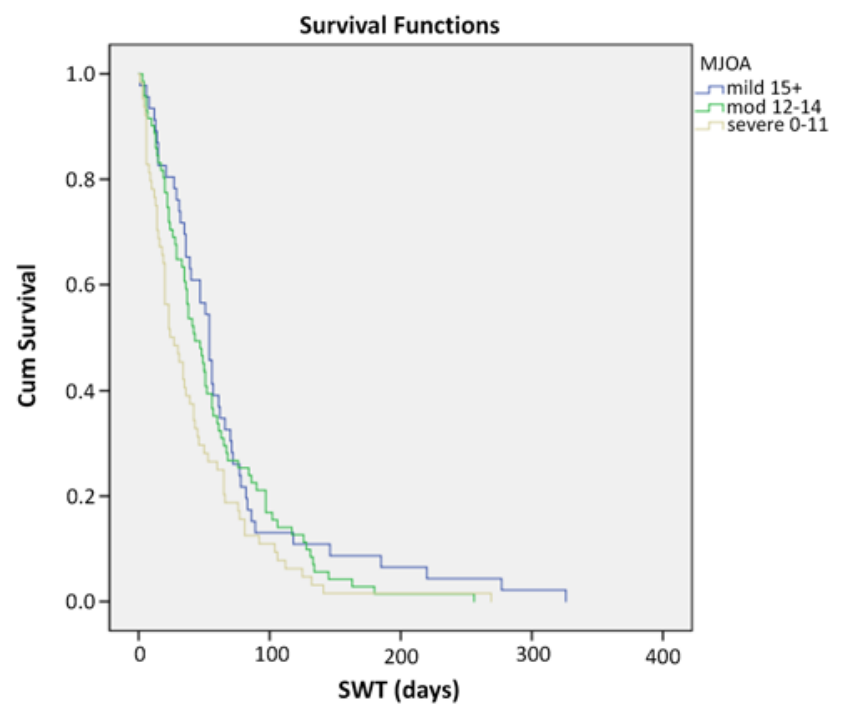

Figure 2: SWT Kaplan-Meier survival curves stratified by disease severity.

\section{CSM and Lumbar Stenosis Comparison}

A query of the CSORN database returned a total of 2799 patients who were surgically treated for lumbar stenosis.
Table 3: Regression analysis of predictors of SWT

\begin{tabular}{l|c|c|c|c}
\hline Predictor & HRR & $\begin{array}{c}\text { 95\% CI } \\
\text { (lower) }\end{array}$ & $\begin{array}{c}\text { 95\% CI } \\
\text { (upper) }\end{array}$ & $\boldsymbol{p}$-value \\
\hline $\begin{array}{c}\text { Medication duration } \\
<1 \text { year }\end{array}$ & 1.914 & 1.272 & 2.881 & .002 \\
\hline $\begin{array}{c}\text { Baseline neck } \\
\text { pain rating }\end{array}$ & .932 & .860 & 1.009 & .083 \\
\hline
\end{tabular}

$\mathrm{HRR}=$ hazard rate ratio and $\mathrm{CI}=$ confidence interval.

Their median CWT was 82 days compared to 46 days for CSM. The median SWT was 69 days for lumbar stenosis compared to 42 days for CSM. Kaplan-Meier log rank tests revealed that both CWT and SWT were significantly shorter in CSM group compared to spinal stenosis group $(p<0.001)$.

\section{Discussion}

To our knowledge, this is the first study to investigate wait times and predictors in patients with CSM. In a public healthcare system such as the Canadian one, knowing the estimated wait time from referral to seeing a spine surgeon and from assessment to surgical treatment is necessary information to assist in quality improvement strategies.

In this study, patients with severe myelopathy waited less than patients with moderate symptoms to see a spine specialist and waited less than the moderate and mild groups to have surgery; however, mJOA on its own was not a significant predictor of wait times. There was no difference between the severe and mild groups for CWT. Two explanations are that our study may have been underpowered to detect a significant difference between each severity category or that the impact of the severity of the disease is indeed more pronounced on SWT than on CWT. Severity of symptoms may be better assessed by a surgeon, and hence the assessment has more impact on SWT. Disease severity may moreover not always be well communicated between referring doctors and surgeons, explaining less impact on CWT. The referral and prioritization mechanisms currently in place do work to some extent, but good communication between referring doctors and spine specialists cannot not be overemphasized. Improving the referral pathway for patients before they become severe would improve healthcare outcomes. ${ }^{10,11}$ Increased awareness and continuous medical education of this common problem are part of the solution.

The other predictors of a shorter CWT were short symptom duration at time of referral, less neck pain, cord compression, 
lower BMI, and lower PCSs. Predictors of shorter SWT, on the other hand, only included short medication duration and less neck pain. Patients with more chronic findings and longer duration of symptoms had to wait longer to receive either consultation or surgical treatment. The rationale for this may be based on the knowledge that duration of symptoms has been shown to have a negative effect on surgical CSM outcomes. ${ }^{10,11}$ Subacute CSM patients are often seen and offered treatment in an expedited fashion, thereby prioritizing patients with the best chance of improvement. ${ }^{10,11}$ The other findings reflect that surgeons are less likely to see and operate rapidly on patients with severe neck pain.

Both CWT and SWT were significantly shorter in CSM compared to lumbar stenosis, which was expected. Our findings suggest that clinically appropriate prioritization schemes have been established at the participating centers. Patients with myelopathy, who have a higher likelihood of deterioration and with potential increased morbidity from delayed management, are treated faster than patients with lumbar stenosis.

The median CWT and SWT in this study were 46 and 42 days, respectively. We were unable to identify published data from other healthcare systems for comparison. Considering the potential clinical deterioration over time and the fact that patients with longer duration of symptoms and more severe disease have worse outcomes, time does matter in CSM. It is critical that CSM be diagnosed promptly, referred and managed in an expedient manner. A delay of close to 3 months from initial referral to definitive treatment may be suboptimal. ${ }^{10,11}$ The length of the wait is an incentive to overcome the obstacles to expedited care. Improving communication and improved referral screening strategies are central to improving CWT. Imaging review by the spinal surgeon, rapid access clinics, and physiotherapist triage clinics are all potential improvement strategies that could improve CWT and needs to be studied further in this population. On the other hand, multiple factors are potential barriers to expedited surgical treatment. Access to semi-urgent operative time, case sharing among surgeons and proactive waitlist management are all part of dealing with limited resources, a problem commonly cited by surgeons to explain increased SWT. Surgery for CSM has been shown to be cost-effective while spinal cord impairment is associated with significant cost and productivity loss. ${ }^{15}$ A combined effort by physicians and funders to increase expedited definitive care for these patients is justified and should be the focus of further study.

One limitation of this study is a lack of generalizability to other healthcare systems; however, the homogeneity of the Canadian healthcare structure increases the validity of these results for any single payer system. Moreover, no difference between provinces was found for both CWT and SWT reinforcing the homogeneity of this healthcare system. Although we acknowledge different referral schemes within Canada, the goal of this paper was not to compare pathway systems, but to define CWT and SWT and potential predictors in Canada and give incentives for improvement for this time-sensitive pathology. Interestingly, however, different screening strategies among different provinces did not impact CWT in this population. We did not establish a correlation between wait times and patient outcomes; our goal was to analyse predictors of shorter wait times. Lastly, we did not address two other potentially significant contributors: the time from symptom onset to first medical assessment and the time taken by primary care physicians to initiate consultation. Physicians will often request different investigations (imaging, nerve conduction studies) prior to making referrals. This "diagnostic" wait time has the potential to be long but needs to be kept to a minimum.

\section{Conclusion}

In this study, symptom severity had an impact on consultation and SWT in patients with cervical myelopathy. Patients with shorter duration (either symptoms or medication) and less neck pain had shorter waits to see a spine specialist in Canada and to undergo surgical treatment. This study highlights some of the obstacles to expedited care in this patient population. Process improvement strategies should be deployed to optimize outcomes in a population of patients in whom time matters.

\section{ACKnOWLedgements}

The authors thank all of the subjects who participated in the study and the support/research coordinator staff and investigators from the CSORN contributing sites: Foothills Medical Centre, Winnipeg Health Sciences Centre, Vancouver General Hospital, Victoria Hospital - London Health Sciences Centre, Queen Elizabeth II - Halifax Sciences Centre Neurology, Hopital de L'enfant Jesus, and University of Alberta hospital site.

\section{CONFLict of InTEREST}

Dr. Fisher reports personal fees from Medtronic, personal fees from Nuvasive, grants from AOSpine, grants from Medtronic, and grants from OREF, outside the submitted work. Dr. Dea reports personal fees from Stryker, personal fees from Medtronic, and personal fees from Baxter, outside the submitted work. Dr. Johnson reports grants from Stryker, outside the submitted work. Dr. Rampersaud reports personal fees from Medtronic, during the conduct of the study and personal fees from Medtronic, outside the submitted work. Dr. Jacobs reports personal fees from Stryker and personal fees from Medtronic, outside the submitted work. Dr. Manson reports grants from Medtronic Canada and personal fees from Medtronic Canada, outside the submitted work. Dr. Christie reports personal fees from Medtronic Canada, grants from Medtronic Canada, and grants from Rick Hanson Institute, outside the submitted work. Dr. Manson reports grants from Medtronic Canada and personal fees from Medtronic Canada, outside the submitted work. All other authors have nothing to disclose.

\section{Statement of Authorship}

BS: concept and design, analysis and interpretation of data, drafting the manuscript, and critical revision of the manuscript. $\mathrm{CF}$ : concept and design, acquisition of data, analysis and interpretation of data, drafting the manuscript, critical revision of the manuscript, and supervision. WBJ: concept and design, acquisition of data, analysis and interpretation of data, and critical revision of the manuscript. MJ: concept and design, acquisition of data, analysis and interpretation of data, and critical revision of the manuscript. CSB: concept and design, acquisition of data, analysis and interpretation of data, and critical revision of the manuscript. SC: concept and design, acquisition of data, analysis and interpretation of data, and critical revision of the manuscript. $\mathrm{RC}-\mathrm{M}$ : concept and design, acquisition of data, analysis and 
interpretation of data, and critical revision of the manuscript. JP: concept and design, acquisition of data, analysis and interpretation of data, and critical revision of the manuscript. AN: concept and design, acquisition of data, analysis and interpretation of data, and critical revision of the manuscript. DC: concept and design, acquisition of data, analysis and interpretation of data, and critical revision of the manuscript. NM: concept and design, analysis and interpretation of data, and critical revision of the manuscript. $\mathrm{HH}$ : concept and design, analysis and interpretation of data, and critical revision of the manuscript. KCT: concept and design, acquisition of data, analysis and interpretation of data, and critical revision of the manuscript. YRR: concept and design, analysis and interpretation of data, and critical revision of the manuscript. GM: concept and design, analysis and interpretation of data, drafting the manuscript, critical revision of the manuscript, and statistical analysis. ND: concept and design, acquisition of data, analysis and interpretation of data, drafting the manuscript, critical revision of the manuscript, and supervision.

\section{REFERENCES}

1. Nurick $\mathrm{S}$. The pathogenesis of the spinal cord disorder associated with cervical spondylosis. Brain. 1972;95(1):87-100.

2. Fehlings MG, Wilson JR, Kopjar B, et al. Efficacy and safety of surgical decompression in patients with cervical spondylotic myelopathy: results of the AOSpine North America prospective multi-center study. JBJS. 2013;95(18):1651-8.

3. Rao RD, Gourab K, David KS. Operative treatment of cervical spondylotic myelopathy. JBJS. 2006;88:1619-40.

4. Uomoto JM, Turner JA, Herron LD. Use of the MMPI and MCMI in predicting outcome of lumbar laminectomy. J Clin Psychol. 1988;44:191-7.

5. Kalsi-Ryan S, Singh A, Massicotte EM, et al. Ancillary outcome measures for assessment of individuals with cervical spondylotic myelopathy. Spine (Phila Pa 1976). 2013 Oct 15; 38(22 Suppl 1): S111-22.

6. Tetreault L, Kopjar B, Nouri A, et al. The modified Japanese Orthopaedic Association scale: establishing criteria for mild, moderate and severe impairment in patients with degenerative cervical myelopathy. Eur Spine J. 2017 Jan;26(1):78-84.

7. Houten JK, Cooper PR. Laminectomy and posterior cervical plating for multilevel cervical spondylotic myelopathy and ossification of the posterior longitudinal ligament: effects on cervical alignment, spinal cord compression, and neurological outcome. Neurosurgery. 2003;52:1081-8.

8. McCormick WE, Steinmetz MP, Benzel EC. Cervical spondylotic myelopathy: make the difficult diagnosis, then refer for surgery. Cleve Clin J Med. 2003;70:899-904.

9. Matz PG, Anderson PA, Holly LT, et al. The natural history of cervical spondylotic myelopathy. J Neurosurg Spine. 2009 Aug;11(2): 104-11.

10. Tetreault LA, Kopjar B, Vaccaro A, et al. A clinical prediction model to determine outcomes in patients with cervical spondylotic myelopathy undergoing surgical treatment: data from the prospective, multi-center AOSpine North America study. JBJS. 2013;95:1659-66.

11. Tetreault L, Wilson JR, Kotter MR, et al. Predicting the minimum clinically important difference in patients undergoing surgery for the treatment of degenerative cervical myelopathy. Neurosurg Focus. 2016 Jun;40(6):E14.

12. Collett D. Modelling survival data in medical research, 2nd ed. London: Chapman \& Hall Inc; 2003.

13. Hasenbring M, Marienfeld G, Kuhlendahl D, Soyka D. Risk factors of chronicity in lumbar disc patients: a prospective investigation of biologic, psychologic, and social predictors of therapy outcome. Spine (Phila Pa 1976). 1994;19(24):2759-65.

14. Sampath P, Bendebba M, Davis JD, Ducker TB. Outcome of patients treated for cervical myelopathy. A prospective, multicenter study with independent clinical review. Spine (Phila Pa 1976). 2000;25:670-6.

15. Tetreault LA, Karpova A, Fehlings MG. Predictors of outcome in patients with degenerative cervical spondylotic myelopathy undergoing surgical treatment: results of a systematic review. Eur Spine J. 2015;24(suppl 2):236-51. 